\title{
A New Photometer
}

This content has been downloaded from IOPscience. Please scroll down to see the full text. 1892 Proc. Phys. Soc. London 12354

(http://iopscience.iop.org/1478-7814/12/1/322)

View the table of contents for this issue, or go to the journal homepage for more

Download details:

IP Address: 141.161.91.14

This content was downloaded on 23/08/2015 at 21:54

Please note that terms and conditions apply. 
Prof. Henrici thought the method would be a very useful one.

Prof. Greenhill said one would now be able to secure better diagrams of transcendental and other curves than heretofore, and he thought Mr. Boys's method would supplant the laborious processes now used to determine the paths of projectiles. When the resistance varied as the square of the velocity, the elevation for maximum range depended on the initial velocity, and for a cube law, both elevation and range tend to finite limits as the initial velocity increases.

Prof. Minchin inquired whether the catenary could be best drawn by using a scale of equal parts instead of one divided reciprocally.

The President greatly appreciated the saving of labour effected by Mr. Boys's method, and thought the apparatus should be shown at the forthcoming Exhibition of Mathematical Instruments in Germany.

\section{A New Photometer. By Alexander P. Trotter*.}

In the course of my investigations on the distribution and measurement of illumination $\dagger$, which led to the examination of the lighting of several streets and public places in London during the winter of 1891-92, I used illuminationphotometers of different kinds. The final form consisted of a horizontal screen of white cardboard, or of paper mounted on glass, having a clear star-shaped hole in the middle. Below this and enclosed in a box was an inclined white screen illuminated by a small glow-lamp. By adjusting the illumination of the lower screen until the star-shaped hole more or less completely disappeared, the illumination of the horizontal screen was measured. After trying several different methods, the illumination of the lower screen was adjusted by altering its inclination to the glow-lamp. I greatly prefer

* Read June 9, 1893.

$\dagger$ "The Distribution and Measurement of Illumination," Proc. Inst. Civil Engineers, vol. cx. pt. iv. Paper No. 2619. 
this arrangement of screens to a Bunsen Photometer, first, because there is only one spot to examine instead of a pair of images, and secondly, because, under favourable conditions, an almost complete disappearance of this spot may be effected, instead of a similarity between two images, as with a Bunsen spot. A Bunsen screen with which the spot disappears on both sides simultaneously is rare. I understand that by warming the grease-spot the edge may be softened, and that simultaneous disappearance may be secured. I have never seen such a screen, and am inclined to think that the disappearance is illusory, and that such softening is probably accompanied by decreased rather than by increased precision.

I have recently applied my arrangement of screens to ordinary light-photometry (as distinguished from illuminationphotometry). My tirst plan consisted of two screens (fig. 1), each inclined at $45^{\circ}$ to the direction of the lights and to the eye. One screen was immediately behind the other; the front screen was perforated, and was mounted on a sliding-carriage on a photometerbar. The lights were placed, the one a little in front and the other a little behind the plane of intersection of the screens. The back of the perforated screen was blackened and was shaded from the light which illuminated the back screen. The edge of the perforation was bevelled, to assist

Fig. 1.

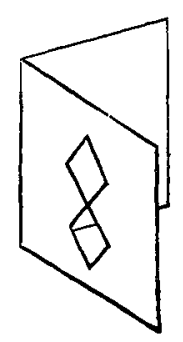
the complete disappearance of the hole. The hole consisted of two lozenge-shaped apertures one over the other, point to point, the object being to concentrate attention on a vertical line. The screens were held in a frame capable of rotation round a vertical axis through a small angle, for the purpose of producing small and rapid variations. But although one screen thus received more light and the other less, the cosine-law of illumination caused the former to increase but slightly in brightness while the latter diminished considerably. It should be observed that this arrangement of screens, although developed from a Bunsen photometer, turns out to be a modification of the Thompson-Starling photometer, in which two screens at $45^{\circ}$ to the lights $*$ and to

* See Nute at end of the Paper. 
the eyo are used, but side by side, instend of one behind the othor.

I showed an extemporized photometor of this kind to Mr. Crompton and to Mr. Swinburno on March 26, 1893. Mr. Crompton suggested the use of zinc for the screens, and this gave me the hint to try perforated zinc, to abandon a definite vertical line of uniform tone, and to select a line or band of uniformity on a screen provided with a number of perforations. I mentioned the iden to Mr. Swinburne on March 27, but had no opportunity of trying it for more than a week. In the meantime Mr. Crompton had thought of a similar expedient, and had used with considerable success a pair of screens, the front one of which was perforated with horizontal slots, and he observed the shading of the slots, say, from bright to dark, and of the bars from dark to bright. Before I had henrd of this morlificntion I had triod vertical bars or slots and perforaterl screons.

The photometer is shown in fig. 2. It consists of $a$ box mounted on a sliding-carringe on 1 photomoter-bar. A slotted screen and a plain screen aro fixed inside, and are

Fig. 2.

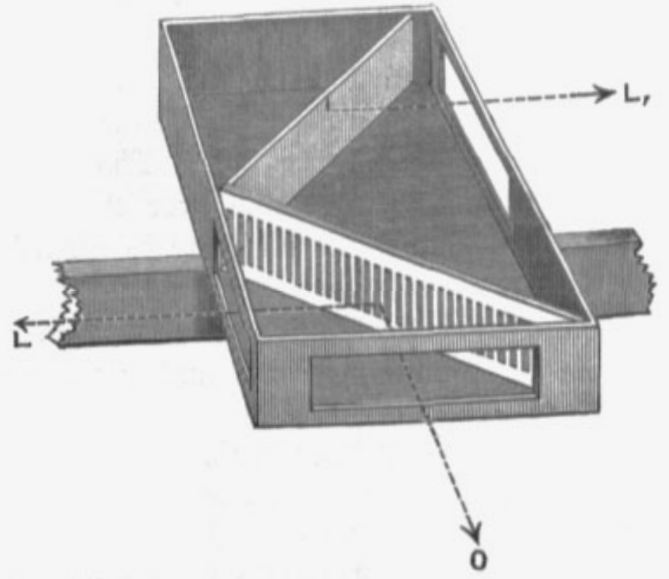

observed through an opening from the direction 0 . The lights fall on the screens through two openings from the directions $L$ and $L_{1}$. The lights are arranged exactly opposite the middle of each side opening, and not in the 
plane of the photometer-bar as is usual. The lower edge of the front opening or diaphragm carries a sight or pointer, and the back screen is provided also with a pointer, preferably at its upper edge. The photometer may be examined from a distance, say six or eight feet, and moved by cords. The two sights should be brought in a line with each other, and the carriage is to be moved until the band of uniform tone is bisected by the pointers. If the carriage be moved slowly it will be seen that the band of uniform tone remains fixed relatively to the scale on the photometer-bar. Readings might be taken by noting the position of the band over the scale, but I prefer to follow the usual custom in photometry, and to keep the scale hidden until an adjustment has been made, to avoid any bias. The operation of estimating the bisection of the band by the pointers is, I think, easier and therefore more conducive to precision than the estimation of the similarity of two images as in the Bunsen, or of two tones as in most other photometers.

I will now give details of the development of this photometer for the guidance of those who may wish to construct them.

Perforated zinc of the ordinary pattern having holes about 0.08 inch diameter and $\frac{1}{8}$ inch pitch, although countersunk on the back and painted dead white on the front, was found to be of no use, probably because the area of the holes was considerably less than that of the remaining metal. Half-inch holes punched in thin card at 0.6 inch pitch gave on the whole a better result than $\frac{1}{4}$-inch or $\frac{1}{8}$-inch wooden slips, bevelled, glued to a frame at a distance apart equal to their width, and painted dead white. I then tried a number of different patterns of perforated zinc and other screens, 30 centim. long by 6 centim. high. Circular perforations of 4 millim. and 6 millim. diameter, about half the metal being removed, were less satisfactory than zinc with holes 13 millim. diameter, rather more than half the metal being removed. A fancy pattern was tried, but without good results. The suitability of the screens was compared in some cases by comparison of the "mean error of a single observation" calculated in the ordinary way from ten measurements, two similar glow-lamps being used, sometimes 2 metres apart, and sometimes 3 metres. 
Finding that thinness of edge and perfect flatness were very important, I made several screens of card and of paper stretched while wet on wooden frames. The coarsest of these consisted of strips of two-sheet Bristol board 8 millim. wide and 8 millim apart, 18 such strips, with an 8 millim. space at each end, making 30 centim. The strips were cut with sharp scissors to avoid any burr on the edge. Another screen has strips 5 millim. wide, and a third has 48 strips 3 millim. wide. White foolscap paper was used, soaked in hot water to remove the glaze ; it was mounted whole, and cut on glass when dry, the knife being held slanting as in mount-cutting, to bevel the edge. These screens I find, and my opinion is confirmed by friends who are for the most part unfamiliar with photometers, to be easy to use.

The advantage of vertical strips is that perfect symmetry is attained, a condition which I find to be important in photometry. When perforations are used, dark holes on a light ground are seen at one end of the screen, and light holes on a dark ground are seen at the other end. The balance is indicated by a strip at which these two patterns become confused. I have not succeeded in getting a definite easily-bisected strip of uniform tint with such screens. When, however, strips are used, the spaces boing equal to the width of the strips, the appearance of the screen is perfectly symmetrical, and the effect is improved by the use of a diaphragm cutting off from the observer the edges of the screens. When lights of similar colour are compared, the light strips and dark spaces at one end are almost indistinguishable from the dark strips and light spaces at the other end. With $8 \mathrm{c.p}$. lamps 3 metres apart, and with the 8 millim. strips, one strip or one space can generally be made to disappear; that is to say, its elges become invisible when examined from a distunce of 6 or 8 feet. At a shorter distance, one eye only must be used. With the 3 millim. st:ips, a nearly uniform grid is scen, paling a little towards the middle, and showing a band about 15 millim. wide, including, say, three strips which are indistinguishable from the two spaces between them. When lights differing in colour are used, the narrow strips are distinctly preferable: disappearance is nowhere complete. hut the differently 
coloured strips and spaces seem to blend at a definite place on the screen.

As screens 30 centim. long and requiring a box about 50 centim. by 30 might be considered cumbersome, 1 have made a photometer with screens $22.5 \times 3.7$ centim. effective; these are contained in a box measuring about $22 \times 32 \times 6$ centim. deep. The diaphragm facing the observer is $15 \times$ 3.5 centim. The screens are placed at $45^{\circ}$ to the lights and to the observer. I have tried other inclinations, but there is no difficulty in getting a surface sufficiently dead-white to work well at this angle.

I find that a distance of 3 metres between two $8 \mathrm{c} . \mathrm{p}$. glowlamps is rather great for easy reading of the photometer. A distance of 2 metres is perhaps a little too small; that is, if a greater distance conduces to greater precision, it might be worth while to employ an intermediate distance. Again, a distance of 3 metres seems suitable for comparing a pair of $16 \mathrm{c.p}$. lamps. This question may be considered from the point of view of a gradient or fall of illumination; and it is not unlikely that for any one observer, the "mean error of a single observation" is a function of the gradient of illumination at the photometer-screen.

With an 8 c.p. lamp at 1.5 metre, the illumination is 3.56 times a candle-metre; that is, it is 3.56 times the illumination which would be given by one candle at one metre. The gradient is 0.0474 candle-metre per centimetre. With a 2-metre photometer-bar and a pair of 8 c.p. lamps, the illumination due to one lamp is 8 candle-metres, and the gradient is 0.16 candle-metre per centimetre. With a $16 \mathrm{c} . \mathrm{p}$. lamp on a 3-metre bar, the gradient at the middle, i.e. 1.5 metre, is 0.948 candle-metre per centimetre. My experience with the form of photometer described in this paper goes to show that a gradient of less than $0 \cdot 1$ candle-metre per centimetre is not desirable. It should be observed that the illumination on a screen inclined at $45^{\circ}$ to the light is about 0.7 of that of a screen turned full to the light.

To graduate a photometer-bar of unit length, and having a unit light at one end, T have used the formula :-

$$
l=\frac{1}{1+\sqrt{n}},
$$


where $l$ is a length measured on the bar, and $n$ is proportional to the light to be measured. With a 3-metre bar a displacement of 3.9 millim. from the middle is equivalent to a difference of 1 per cent. in the candle-power of the two lights. Since the band of uniformity with the 3 millim. strips may be said to be about 15 millim. wide, and 15.6 millim. are equivalent to 4 per cent., it is only by bisection of this band that a precise measurement can be made. In using the 8 millim. strips, if the middle of one strip or space is the actual point of balance, and by error the space or strip on one side of it be taken as the one indicating the balance, the error is \pm 2 per cent. Out of several series of 1.2 observations, the mean error of a single observation has frequently fallen below this. Among some results which I consider satisfactory, compared with my experience with other photometers, are mean errors of 0.85 and of 1.48 per cent. calculated from sets of 12 readings.

\section{Note added June 5, 1892.}

In further tests with this photometer the mean errors have generally fallen below 1 per cent.

At first I tried other angles than $45^{\circ}$. For whitewashed metal screens this angle appears to be suitable. I find, however, that it is preferable with paper screens to use an angle of incidence of $35^{\circ}$, and I understand that this angle is used in the Thompson-Starling photometer.

When the light to be measured is subject to small variations, the direction and the magnitude of the variations are piainly visible by the movement of the band of uniform tone. This photometer has been chiefly used for such measurements, and seems to be well adapted for them. 